\title{
Content-Based Approach in Exploring the Cognitive Structure of Values
}

\author{
Johanna Maksimainen $^{1}$ \\ ${ }^{1}$ Department of Computer Science and Information Systems, University of Jyväskylä, Jyväskylä, Finland \\ Correspondence: Johanna Maksimainen, Department of Computer Science and Information Systems, University \\ of Jyväskylä, PO box 35, Jyväskylä 40014, Finland. Tel: 358-400-248-129. E-mail: \\ johanna.maksimainen@jyu.fi
}

Received: February 2, 2012

Accepted: March 13, 2012 Published: May 1, 2012

doi:10.5539/ass.v8n6p26

URL: http://dx.doi.org/10.5539/ass.v8n6p26

\begin{abstract}
This article discusses the content-based approach in examination of values. In the content-based approach, human thinking in different contexts is set at the focal point, and attention is devoted to those cognitive processes through which mental representations are constructed. The information contents of mental representations play a decisive role in understanding human behavior. By applying content-based analysis to an examination of the conceptual contents of human values, it is possible to reach a deeper understanding of the cognitive structure which lies as the motivational foundation of actions. In this article, it is argued that different informational contents of values explain variance actualized in behaviors. A suggestion for a model of cognitive structure of values is presented. The model illustrates different information contents related to particular object.
\end{abstract}

Keywords: content-based approach, mental content, mental representations, values

\section{Introduction}

Value research covers a wide spectrum of analyses executed within a variety of disciplines related to the study of human values. From classical Greece to contemporary social science, the integrative conviction within this research tradition is based on the recognition that values matter. Despite the use of the term in a variety of literature, very little consensus exists on what constitutes a value (e.g., Kluckhohn, 1951/1954; Rokeach, 1968, 1973, 1979; Payne, 1980; Kilmann, 1981; Wiener, 1988; Borg, 1990). Values have been attached to beliefs (Rokeach, 1968, 1973), needs (Super, 1973), criteria for choosing goals (Locke, 1976), goals (Schwartz \& Bilsky, 1987), and attitudes (Eagly \& Chaiken, 1993). Despite the unquestionable success of value theories and studies in revealing the functions, meanings, and construction of human values, relevant problems may be related to the conceptual construction of such values, which do not open in a natural manner to the traditional value theory languages. Therefore, in this article, the content-based reference frame is suggested as an alternative approach to the examination of values, and as a complementary paradigm to contribute to structuring a more solid conceptual foundation for value research. The content-based approach (Saariluoma, 1990, 1995, 1997, 2001, 2002, 2003a) was developed for investigating human thinking. The emphasis is on the mentality of experiencing and explaining human behavior in terms of information content of mental representations and processes involved in constructing these representations. Thus, in content-based research, the information contents of mental representations form the explanatory basis for exploration. In this article, the focus is on the concept of value, which is discussed in terms of mental representation.

Since Schwartz's (1992) circular model of values was published in Advances in Experimental Social Psychology nearly 20 years ago, the understanding of the values and their functioning has significantly grown. Studies of diverse processes related to values have indicated that the model actually reflects accurately peoples' mental representations of values. The model predicts patterns in the accessibility of values from memory, the effects of value priming on behavior, feelings of ambivalence toward others, and patterns of value changes. Together, these kinds of findings indicate that mental representations of values include an aspect wherein values are interconnected via the motivational objectives that values denote. Processing of a specific focal value is related to other values operating in the background. However, there are differences in mental representations between individuals. Mental representations are constructed on the basis of different types of stimuli, but also by previous 
personal conceptual knowledge (e.g., Saariluoma, 2002). When the objective is to understand conceptual structures of values, the contents of mental representations must be analyzed by paying attention to different types of conceptual content. Evidently, people differ greatly in their values, and these differences can be parsed only by expanding analysis to examine how conceptual contents of mental representations sustain the importance of particular values. This requires examining the information that is processed in peoples' minds when they indicate that certain values are important to them. Affective, behavioral, and cognitive information may all advance to determine the importance of values in mental representations. For understanding the effects of values on behavior, we must consider how people shift from the abstract representation of a value to specific behaviors.

Value theories cover and encompass diverse approaches to understanding how, why, and to what degree people value, or should value, ideas, objects, or anything else. The main argument is that different conceptions of values explain different actions. However, the primary interest concerns the conceptual construction of values. The content-based approach is presented in this article as a complimentary approach to exploring values. According to this approach, through differences in content elements of mental representations of values, it is possible to explain differences in human behavior. Through the content-based approach, it is possible to achieve a psychologically grounded understanding of the conceptual structure of values. In this article, after the introduction to values and content-based approach, the suggestion for a model of the structure of values is presented.

\section{Values}

Generally, values are rules by which individuals make decisions about right and wrong. Values help us perceive which values are more or less important, or which is useful when one have to choose one value over another. They can also be described as culturally shared conceptions of what is desirable, they play a central role in directing actions, and they are considered according to their relative importance (Schwartz \& Bilsky, 1987). Although there is a lack of consensus about the constitution of values, most theorists agree that values are standards or criteria (Kluckhohn, 1951/1954; Rokeach, 1973; Kilmann, 1981; Schwartz \& Bilsky, 1987) for choosing goals or actions and are relatively stable over time (Kluckhohn, 1951/1954; England, 1967; Rokeach, 1973). It is commonly proposed that values develop through the influences of culture, society, and personality.

Once internalized, a value system functions in several ways, affecting an individual's perceptual processes in the manner that external stimuli are perceived in ways that are in consistency with that individual's value structure (Postman, Bruner \& McGinnies, 1948; Williams, 1979). Values also serve to legitimize operations, providing justifications for an individual's behavior (Williams, 1979; Nord, Brief, Atieh \& Doherty, 1988), and directly affecting behavior, encouraging individuals to act in accordance with their values (e.g., Rokeach, 1973; Williams, 1979). In this sense, values have significant role in affecting individuals' behavior (Rokeach, 1973). Besides other constructs that are essential in understanding human actions, values affect general modes of behavior across situations and over time (Epstein, 1979). The psychological mechanisms responsible for values' effects depend partly on whether the behavior is public or private. Since values designate socially desirable modes of conduct, the threat of social sanctions such as shame induces individuals to conform to dominant social values in their public actions (Kluckhohn, 1951/1954).

Values occupy a prominent place in both scientific and public discourse at several levels. For instance, values have a significant effect on individuals' affective and behavioral responses (e.g., Rokeach, 1973; Locke, 1976), on intended increases in unethical business practices (e.g., Mitchell \& Scott, 1990), and on employees' problems in organizations (e.g., Nord et al., 1988). At the organizational level, values are usually described as principles that are responsible for successful management (e.g., Mitchell \& O'Neal, 1994). Generally, values are viewed as a salient component of organizational culture (Schein, 1985; O'Reilly \& Chatman, 1996). Despite of the popularity of values as object of research, however, there is not a clear consensus on the nature of values. They have been conceived as motivations, goals, attitudes, personality types, interests, needs, and mental entities. The absence of agreement (e.g., Kluckhohn, 1951/1954; Williams, 1979; Rokeach \& Ball-Rokeach, 1989) has lead to difficulties in interpreting the results of studies, and steers the need for greater agreement on how values are defined, conceptualized, and measured, especially in organizational research (Connor \& Becker, 1979, 1994). Evidently, values play a prominent role in directing human actions as abstract concepts with different conceptual contents.

From the viewpoint of a content-based approach, the key interest is in categorizing the concepts that individuals use in their interpretations. To achieve a more comprehensive understanding of such structure, close attention should be paid to concepts that are used in the process of interpretation. According to Kuhn (1962/1970), different paradigms of a particular discipline are incommensurable. Sellars, instead, notes that talk of reasons, 
epistemic justification, and intention is not the same as, and cannot necessarily be mapped onto, talk of causes and effects in the sense that physical science speaks of them. Sellars does not believe that describing and explaining are the only dimensions of linguistic activity, but that prescribing, evaluating, and negotiating are equally indispensable dimensions of language use in which science is not privileged (Sellars, 1956/1997). However, there is a change of central concepts and presuppositions of content-based analysis. For example, in Schwartz's theory of human values, they are not exclusive in relationship to each other, but rather, complementary. The relevant problems and research objectives are defined in different manners within these disciplines. The main point here is that mental contents may provide the important conceptualization that is equal to more standardized views of human values. Content-based analysis can be used in solving different types of problems from those considered in more traditional disciplines, in which values are conceived, for example, as motivational bases of action or attitudes, without examining their conceptual contents. While science progresses, the assumptions of previous paradigms do not necessarily have to be abandoned. Instead, ways to match them with research problems to which they can provide answers must be found. After all, communication between different disciplines may better reveal the phenomenon under examination as a whole, and combining perspectives can add lend accuracy to the explanation behind such phenomenon.

\section{Content-Based Approach in Examination of Values}

The fact that values are both concrete and abstract creates a challenge to value research. Individuals refer to values in ways that are abstract, but when they apply values, they must do so concretely. Therefore, in this article, the basic assumption is that the existence of values at both those levels is understood by explicitly regarding values as mental representations; among other features, values vary in concreteness, accessibility, connections to other constructs, and their applicability to other judgments. Since the development and application of any value should be intricately connected to development and application of other values, this notion is important for comprehending values as mental representations.

The information contents of mental representations comprise the explanatory ground of examination in content-based psychology (Saariluoma \& Nevala, 2006). In a content-based approach, clarifications of the functions of content-specific modes of thinking, such as apperception, restructuring, reflection, and construction, in different contexts of problem-solving activities are at the core of attention. When a particular issue is considered a "value," it requires the individual's interpretation of that issue. Therefore, human values can be considered one type of problem-solving activity. In interpretations, which are closely related to the problem of experience, the mental contents related to a particular value are constituted through the different modes of thinking mentioned above, as well as through the concepts of memory and attention.

The construction process of mental representation is somewhat different from more concrete concepts if we examine the contents of mental representation of abstract concepts, such as values that function as the basis for making judgments and decisions in everyday life. In this context, the expression abstract concept refers to concepts that do not indicate to any perceptual object. Representations' non-perceivable (non-conceptual) content elements are in these cases more emphasized. The distinction between perceivable and non-perceivable content elements is important in scrutinizing mental representations (e.g., Saariluoma, 2002). Non-perceivable concepts have no physically perceivable equivalents. Instead, their equivalents are abstract concepts. These types of concepts have equivalents in the physical world such as representation of a concept as behavioral actualizations. For example, the value concepts success, equality, and justice have different types of actualizations in the physical world, depending on their contents. Although value concepts are quite problematic in the sense that their contents can be highly abstract, every value concept has a set of attributes. Yet, some notions of these non-perceivable contents - or invisible qualities of mental representations - should be made. The meaning of values' non-perceivable mental contents depends on interpretation, but on the other hand, the meaning derives from distinct strategies that individuals use in rationalizing their mental representations through apperception. From the perspective of a content-based approach, the differentiation between perceivable and non-perceivable concepts is important, since it is comparable to the distinction between perception and apperception: apperception integrates non-perceivable contents into one's mental representation based on one's earlier conceptual knowledge (Saariluoma, 2002). The use of non-perceivable concepts usually requires combining information received through different resources and cultural-historical knowledge.

Based on the nature of values as abstract concepts, the entities they represent exist in an individual's network of concepts, i.e., different types of conceptual content elements associated with mental representations and referring to a certain value concept. The conceptual contents of mental representations refer to meanings of particular entities constituted through interpretation processes in individuals' minds. Previous instances seek to explain what meaning is, or what the meaning of expressions in a language consists of. 


\subsection{Theories of Mind}

Representationalism is the view that representations are the main way individuals access external reality. Representational theories of the mind, which go back as far as Aristotle, start with the notion of commonsense mental states, such as thoughts and perceptions, and understand that thinking occurs within an internal system of representation. The dominating contemporary version of the Representational Theory of Mind (RTM), the Computational Theory of Mind (CTM) (Turing, 1936, 1950; Newell \& Simon, 1972; Fodor, 1975), states that the brain is a kind of computer, and consequently, mental processes are computations. The historical foundation for approaching the human mind as a computational system derives from Turing (1936) and his definition of computation and absolute limitations on what computation can achieve. Turing's (1936) core idea depends on the self-reference involved in a machine operating on symbols, which is itself described by symbols and so can operate on its own description. Turing's formulation of computability encompasses "the possible processes which can be carried out in computing a number" (Turing, 1936). This established new fields in practical computation and started the discussion about human mental processes.

The notion of mental representation is, however, arguably in the first instance a theoretical construct of cognitive science. As such, it is a basic concept of CTM, according to which cognitive processes and states are constituted by the prevalence, transformation, and storage of information-processing structures. RTM advances CTM by attempting to explain all psychological processes in terms of mental representation by constructing empirical theories of human cognition and developing models of cognitive processes that can be implemented in artificial information-processing systems. The commonsense mental states, such as thoughts and perceptions, can be seen as the starting points of RTM. These states are argued to have intentionality: they are about or refer to things, and therefore can be evaluated with respect to properties like consistency, truth, or accuracy. In terms of RMT, such intentional mental states are defined as relationships to mental representations. RMT explains the intentionality of the former in terms of the semantic properties of the latter.

The propositional attitudes of the mind are conceived as mental representations with semantic properties. The original representational theory, which was a dominant theme in classical empiricism in general, can probably be traced back to Hobbes. According to this early version of the theory, mental representations were images of the objects that states of affairs represented. For modern adherents such as Fodor (Fodor \& Pylyshyn, 1988; Fodor, 1997), the representational system consists rather of an internal language of thought. The contents of thoughts are represented in symbolic structures that possess a syntax and semantics very much like those of natural languages. In the context of the semantic contents of thought, Vygotsky's (1962) view of the social origins of speech and the higher mental functions must be mentioned. His theory is characterized by concepts of human sociability, social interaction, sign and instrument, culture, history, and higher mental functions. Vygotsky analyses the relationship between words and consciousness, arguing that speech is social in its origins and that only as children develop does it become internalized verbal thought. Learning reinforces this process by making available culture-generated tools that extend the natural possibilities of the individual and restructure his or her mental functions (Vygotsky, 1962; Schaffer, 1971; Thoman, 1979; Lamb \& Scherrod, 1981).

Within contemporary philosophy of the mind, the supposition that the mind can be naturalized, meaning that all mental facts have explanations in terms of natural science, is general. The conception is also shared with cognitive science, which attempts to account for mental states and processes in terms of brain features and the central nervous system. As a result, the various sub-disciplines of cognitive science describe different structures and processes, some of which are not directly implicated by mental states and processes as conceived by commonsense. However, there is a shared engagement to the concept that mental states and processes can be explained in terms of mental representations.

\subsection{Mental Representation}

Extending the notion that a representation is an object with semantic properties, like content, reference, truth-value, and so on, a mental representation may be more widely construed as a mental object with semantic properties. As such, mental representations and involved states and processes cannot be comprised only of computational terms. Computational thinking is based on insight about the human mind as a computational device (Turing, 1936, 1950), in which a set of naturally meaningless symbols are manipulated by a set of functions. It is also possible to see human beings this way, as symbol- manipulating devices (Newell \& Simon, 1972). It is possible to posit that a computational model describes minimal conditions for a thought process (Newell \& Simon 1972), because devices like calculators can perform as humans do, but the way they operate does not clarify anything about human thinking. Therefore, a content-based approach is selected as a framework for exploring HTI design values. Hence, the differentiation between computational and content-based analyses of 
designers' minds should be made. The meta-scientific assumption behind content-based analysis is the notion that the contents of thoughts cannot be expressed by means of computational theory languages, and therefore, the approach is theoretically independent of such mindset. The difficulty of computational approaches relates to the issue that if machines are abstracted, aspects of mental contents are lost. Additionally, on computational grounds, interpretations are impossible to justify. In other words, it is possible to construct simulation models that imitate the content aspects of the human mind, but it is not possible to justify the models on formal grounds only. Therefore, in the analysis of human mentality, the theoretical concepts of content-based analysis are needed. HTI design, along with values involved in the processes, is a representative example of a problem that cannot be created only by computational models. The foundation of differences between individuals' actions lies in the mental contents, if on a formal level.

There is no consensus about the format of mental representations. For example, there have also been discussions also about the claim that conceptual representations lack phenomenology. It is claimed that purely conceptual representational states themselves have a phenomenology (Flanagan, 1992; Searle, 1992; Goldman, 1993; Chalmers, 1996). This claim raises the question of what the role of phenomenology is in determining content that re-appears for conceptual representation. Debates have also concerned the issues of whether mental imagery is a pivotal concept in psychology that strives to explain human information processing. The advocates of imagery have claimed that the concept of mental images should not be abandoned (e.g., Wraga \& Kosslyn, 2003), whereas opponents assume that it is possible to converse about these images by means of propositional code. However, examining mental contents of values, the propositional approach (e.g., von Wright, 1963) seems reasonable, since in individuals' minds, the concepts that are related to a particular value are not necessarily conceptualized, yet are conscious.

Within realists' traditional assumptions about mental representations, representational states come in two basic varieties (Boghossian, 1995). Some thoughts are composed of concepts, having no phenomenal, "what-it's-like" features (qualia), and some, such as sensations, have phenomenal features but no conceptual foundation. Mental states can be analogous either to natural language or to visual stimuli, like pictures, in this classification. For example, in the context of human values, a perceptual state such as experiencing something as important can be thoughts of a hybrid state consisting of a non-conceptual belief and sensation, or can be a more integrated combination of conceptual and non-conceptual elements. Disputes over non-conceptual representation concern the existence and nature of phenomenal properties and their role in determining the content of sensory experience. For example, Dennett (1988) denies the existence of such qualia as they are regularly construed. Rey (1991), McDowell (1994), and Brandom (2002), for example, deny that qualia are even needed to explain the content of sensory experience. Historical discussions about representational properties of mind (e.g., Aristotle, circa 330 BCE/1984; Locke, 1689/1975) reflect the assumption that non-conceptual representations, percepts, are only types of mental representations. The mind represents the reality of being in a state of resembling things in it. Therefore, representational states have contents by virtue of their phenomenal features. This view is criticized for lack of generality (Berkeley, 1975) and non-compositionality of sensory and imagistic representations (Fodor, 1981). There have been discussions also about the claim that conceptual representations lack phenomenology. It is claimed that purely conceptual representational states themselves have a phenomenology (Flanagan, 1992; Searle, 1992; Goldman, 1993; Chalmers, 1996). This claim raises the question of what the role of phenomenology is in determining content that re-appears for conceptual representation. Debates have also concerned the issues of whether mental imagery is a pivotal concept in psychology that strives to explain human information processing. The advocates of imagery have claimed that the concept of mental images should not be abandoned (e.g., Wraga \& Kosslyn, 2003), whereas opponents assume that it is possible to converse about these images by means of propositional code. Examining mental contents of values, the propositional approach (e.g., von Wright, 1963) seems reasonable, since in individuals' minds, the concepts that are related to a particular value are not necessarily conceptualized, yet are conscious. However, to arrive at information about the contents of values, they must be studied in terms of these contents.

\section{Modeling the Structure of Values}

The comprehensive understanding of the relationship between human values and behavior consists of complex cognitive phenomena that cannot be reached through traditional, inquiry-based methods or traditional theoretical frameworks that are typically utilized in values studies. However, could a content-based view of values offer a complementary theoretical reference for describing and measuring the cognitive mechanisms of construction of values? Through new perspectives, knowledge concerning the construction of values should significantly increase.

Values can be very complicated objects as concepts. For example, the interpretations of ethical value concepts 
such as freedom and equity include several different aspects. When studying them, one can find partial solutions to one's questions, such as what symbolic, practical, or ethical meanings are the concepts are associated with. However, in addition to examining the structure of values, the aspects in which values are applied and actualized through human actions should be discussed. Table 1 illustrates examples of questions related to these aspects.

Table 1. Examples of related issues in actualizing specified aspects of values (Maksimainen, 2011)

\begin{tabular}{ll}
\hline Aspect & Examples of related questions \\
\hline Philosophical & How are particular decisions justified? \\
Practical & What benefit does a particular decision produce? \\
& $\begin{array}{l}\text { Does the particular decision result in unwanted consequences? } \\
\text { Human }\end{array}$ \\
& $\begin{array}{l}\text { What values direct the decisions? } \\
\text { What is considered important? }\end{array}$ \\
Socio-Cultural & $\begin{array}{l}\text { Do the results of particular decisions serve society in an ethically } \\
\text { sustainable manner? } \\
\text { How are the values of surrounding cultures taken into account in } \\
\text { particular decisions? }\end{array}$ \\
\hline
\end{tabular}

Philosophical, practical, human, and socio-cultural aspects of values represent the examples of aspects in which values relate and are to be interpreted in decision making situations.

These philosophical, practical, human, and socio-cultural aspects of values represent the examples of aspects in which values relate to and are to be interpreted in decision-making situations. The philosophical aspect refers to the meta-level of values, where judgments of what is desirable, or morally good in itself, are made. The second aspect is practical, referring to instrumental values with some abilities. The human aspect indicates the actor and constructivist comprehension of the individual as a locus of knowledge construction. The human aspect is defined by an individual's personal preferences, competencies, and so on. The last aspect is socio-cultural, referring to those relationships in which values actualize. Philosophical, practical, and socio-cultural aspects of values can have their meanings only through individual information processing. As noted, interpretations are construed linearly piece by piece; first one element, then the second, and finally the interpretations that were given to singular elements are combined into a coherent whole. In this meaning, construction is important in the context of value interpretation. The aspects of values presented above illustrate the types of general-level questions that need to be answered when interpretations are construed in specific situations. Values are not just abstract entities. Instead, they take form in decisions that are made and the behavior that results from such decision-making. Generally, from a psychological viewpoint, values play a significant role in becoming conscious of the reality.

The model of the structure of values is based on the results of the authors' earlier research project (Maksimainen, Saariluoma, Jokivuori, 2010; Maksimainen \& Saariluoma, 2010, 2011) in which the values of human-technology interaction (HTI) designers were examined. However, scientifically, the most significant finding of this research was the view of values through their contents. Through the analysis of contents, the essence of what values actually are, both in individuals' conceptions and as actualized behaviors, can be reached. Previous research is connected to tradition that derives from Westermarck and his empirical research of ethics (Westermarck, 1891/1925). The content-based approach applied in the research aims to provide grounds for investigating the relevant types of mental processes constituting the conceptual contents of mental representations of values, and to discuss whether a content-based view of values could complement a theoretical reference frame for describing and measuring such cognitive mechanisms. In psychology, the phenomenon of mental contents is used to explain human actions and behaviors, and can be structured as the psychology of mental contents (Saariluoma, 2003a; Saariluoma \& Nevala, 2006). Content-based psychological research has been applied earlier, for example, in user psychology, in which users' mental processes, motives, and emotions are investigated during interactions (Moran, 1981; Saariluoma, 2004; Oulasvirta \& Saariluoma, 2004, 2006). To the present study, content-based analysis of design mental contents allows an important addition to a rather unelaborated concept of value with more refined psychological, sociological, and analytical notions.

Results of empirical studies have shown the differences in value structures that illustrate a structural model of values as mental representations. The results show the value concepts that participants thought held importance and the relationships between these concepts, which are called value orientations. Value orientations that are compounded of different conceptual contents can be understood as conceptual perceptions of mental 
representations that differ among the sample. The structure of values in the study wherein the objective was to explore how respondents' mental models of organizational relations (factors Human Resource Management [HRM] and Human Capital Management [HCM]) affect the experienced importance of Corporate Social Responsibility (CSR). As different value-sets, HRM represents the respondents' views on the organization's external processes, whereas HCM refers to respondents' views on the organization's internal processes in terms of conceptual contents (Maksimainen \& Saariluoma, 2010). The main finding was that the HCM approach predicted significantly stronger CSR internalization than did the HRM approach. A high correlation between factors for both HRM and HCM implies that the two perspectives should be seen as mutually reinforcing rather than contradictory. CSR factor seems to be more closely associated with the HCM orientation. This means that advancing CSR in an organization's internal process and personnel with HCM orientation is more sensitive to the issue. The model of the structure of values is illustrated in Figure 1.

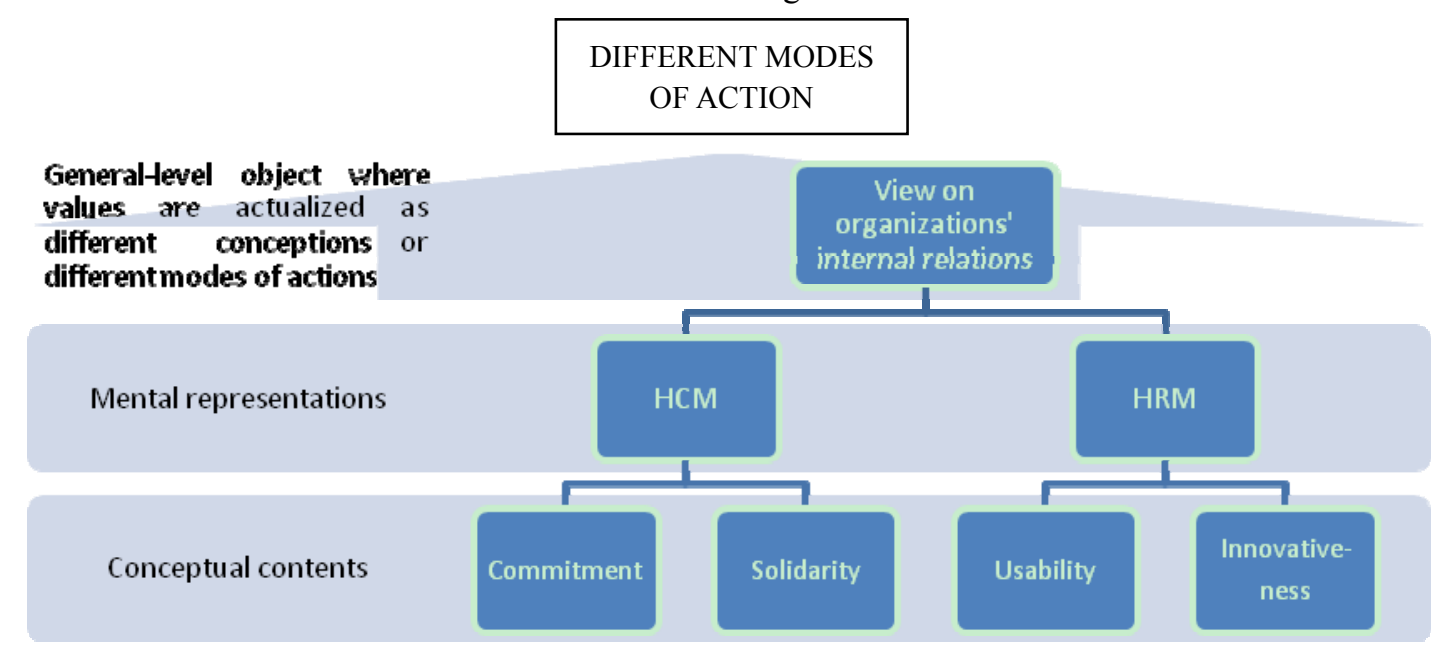

Figure 1. Structure of values

In the example of the hierarchical structure of values, HRM (Human Resource Management) and HCM (Human Capital Management) have different views of organizations' internal relationships, resulting in different modes of action.

In the example, HRM (Human Resource Management) and HCM (Human Capital Management) have different views of organizations' internal relationships. The hierarchical structure does not reveal the experienced importance of values, but rather, the relationship of particular concepts. In the empirical study, two different value orientations, i.e., conceptual contents, were specified that were associated with the views. The illustration does not reveal the cognitive processes involved in the construction of mental representations in either the case of HCM or HRM, or generally. Nonetheless, the structure of values must be exposed to their contents to have meaning. In future studies, to understand the roles of cognitive processes in generating meanings into mental representations, the processes of interpretation, apperception, restructuring, reflection, and construction must be studied. Even if in peoples' experience, the importance of values may be structured hierarchically, the associations between conceptual elements are supposedly associated with each other more randomly. Fig. 1, below, presents a result from a study that was executed with a structured inquiry: the value concepts were defined by the researcher. If participants were allowed to describe freely the concepts they attached particular value to, the structure and relationships of concepts would presumably seem different. However, the model should be tested further in future studies in order to explore the conceptual structure of values and the relations between value conceptions.

\section{Conclusions}

The focus of this article is on understanding the structure and differences in conceptions of values through their contents. By facilitating content-based points of view, it is possible to achieve a psychologically grounded understanding of the conceptual structure of values, as well as the variance actualized in behaviors. A change of behavior derives from a change of conception, conducted through apperception, restructuring, reflection, and construction. The analysis of mental contents is related to mental representations of values in different contexts, for example in the work environment, and can be used to explain differences in individuals' behavior. When applied to examination of human values, the notions of apperception, restructuring, reflection, and construction, which are promoted within a content-based approach, emphasizes the understanding of individuals as active producers of meanings. Through the previous concepts, the problems of conflicting interpretations or 
conceptions of values, for example, within the work community, can be approached. From this viewpoint, content-based approach works as a mean in meta-theoretical discussions in cross-disciplinary value studies. For example, there are possibilities for interactions between content-based approach and ethics. In philosophical ethics, there is plenty of literature about the issues of ethical problem-solving, wherein values are naturally involved, such as conflicts of values, or rights, or professional responsibilities. In the future, these themes related to content-based examination of experiencing values should be studied in more detailed ways. How philosophical and empirical approaches to issues of experiencing values can be imported into contact with each other in a way that the results benefit both fields should also be investigated further.

One important task in future research is to deepen the theoretical frame of content-based analysis by both experimental examinations and conceptual analysis, and specifically in the context of value studies, to develop relevant measure methods that are in accordance with a content-based approach. In studies of mental contents of individuals interpreting their values, the data collected in experimental situations are crucial, since such data reveal the instantaneous process of thinking. Naturally, experimental situations may limit the freedom of construction of participants' interpretations. Another limitation is that the conceptual contents of values construct and reconstruct during a long time period, which constitutes a major difficulty for building an experimental situation with high validity. Despite certain limitations, more comprehensive understanding of experiencing values in the context of HTI design is possible by creating different experimental settings and combining the results of various data types. Qualitative data can reveal those individual differences that may appear in human experience of values, whereas quantitative analysis can provide a general view of the typical features of the data. The significance of a content-based approach to experiencing values derives from the notion that better understanding of mental processes that direct the perception of values and interacts with emotions should be reached.

A content-based reference frame can also be applied to investigating the changing conceptions of values during different periods of time. Through analysis of written documents, which can vary from newspaper writings to national information society vision manifests, the conceptions of values and conscious manipulation of values and attitudes of the audience can be investigated. By analyzing the conceptions presented in such documents by different instances, it is possible to become more conscious of the contents of human experience of values. With systematic conceptual analysis, the intuitive aspects of human values can be recognized. After all, the significance of a content-based approach to experiencing values derives from the notion that better understanding of mental processes that direct the perception of values and interacts with emotions should be reached. In many cases, values tend to be emotionally charged, both as concepts and in human experiences. From an individual's perspective, they are constantly present, affecting one's actions quite holistically, but values and value-related information are also all around in an individual's external reality. Therefore, in the future, it is important to extend the scope of a content-based approach to cover more widely the sphere of narrative and visual surroundings, as well as products that are present in people's everyday lives.

\section{References}

Aristotle. (circa 330 BCE/1984). De Anima. The Complete Works of Aristotle: The Revised Oxford Translation. Oxford: Oxford University Press.

Berkeley, G. (1975). Principles of Human Knowledge. In Ayers, M.R. (Ed.), Berkeley: Philosophical Writings. London: Dent.

Borg, I. (1990). Multiple Facetisations of Work Values. Applied Psychology: An International Review, 39, 410-412.

Brandom, R. (2002). Non-Inferential Knowledge, Perceptual Experience, and Secondary Qualities: Placing McDowell's Empiricism. In Smith, N.H. (Ed.), Reading McDowell: On Mind and World. London: Routledge.

Chalmers, D. (1996). The Conscious Mind. New York: Oxford University Press.

Connor, P.E., \& Becker, B.W. (1979). Values and the Organization: Suggestions for Research. Academy of Management Journal, 18, 550-561. http://dx.doi.org/10.2307/255684

Connor, P.E., \& Becker, B.W. (1994). Personal Values and Management: What Do We Know and Why Don't We Know More? Journal of Management Inquiry, 3, 67-73. http://dx.doi.org/10.1177/105649269431011

Dennett, D. (1988). Quining Qualia. In Marcel A.J., \& Bisiach, E. (Eds.), Consciousness in Contemporary Science (pp. 67-73). Oxford: Clarendon Press.

Eagly, A.H., \& Chaiken, S. (1993). The Psychology of the Attitudes. Orlando: Harcourt Brace Jovanovich.

England, G.W. (1967). Personal Values Systems of American Managers. Academy of Management Journal, 10, 107-117. http://dx.doi.org/10.2307/254630 
Epstein, S. (1979). The Stability of Behavior: 1. On Predicting Most of the People Much of the Time. Journal of Personality and Social Psychology, 37, 1097-1126. http://dx.doi.org/10.1037/0022-3514.37.7.1097

Flanagan, O. (1992). Consciousness Reconsidered. Cambridge, MA: The MIT Press.

Fodor, J. (1975). Propositional Attitudes. The Monist, 61, 501-523.

Fodor, J., \& Pylyshyn, Z.W. (1988). Connectionism and Cognitive Architecture: A Critical Analysis. In Pinker, S., \& Mehler, J. (Eds.), Connections and Symbols. Cambridge, MA: The MIT Press.

Fodor, J. (1981). The Present Status of the Innateness Controversy. In Fodor J. (Ed.), Representations (pp. 257-316). Cambridge, MA: The MIT Press.

Fodor, J. (1997). The Representational Theory of Mind. American Behavioral Scientist, 40, 829-841. http://dx.doi.org/10.1177/0002764297040006010

Goldman, A. (1993). The Psychology of Folk Psychology. Behavioral and Brian Sciences, 16, 15-28. http://dx.doi.org/10.1017/S0140525X00028648

Kilmann, R.H. (1981). Toward a Unique/Useful Concept of Values for Interpersonal Behavior: A Critical Review of the Literature on Value. Psychological Reports, 48, 939-959. http://dx.doi.org/10.2466/pr0.1981.48.3.939

Kluckhohn, C. (1951/1954). Values and Value Orientations in the Theory of Action: An Exploration in Definition and Classification. In Parsons, T., \& Shills, E.A. (Eds.), Toward a General Theory of Action (pp. 388-433). Cambridge, MA: Harvard University Press.

Kuhn, T.S. (1962/1970). The Structure of Scientific Revolutions. Chicago, IL: University of Chicago Press.

Lamb, M.E., \& Scherrod, L.R. (1981). Infant Social Cognition. Hillsdale, NJ: Lawrence Erlbaum Associates.

Locke, E.A. (1976). The Nature and Consequences of Job Satisfaction. In Dunnette M.D. (Ed.), Handbook of Industrial and Organizational Psychology (pp. 1297-1349). Chicago: Rand McNally.

Locke, J. (1689/1975). An Essay Concerning Human Understanding, edited by Nidditch, P.H. Oxford: Oxford University Press.

Maksimainen, J. (2011). Aspects of Values in Human-Technology Interaction Design - A Content-Based View to Values. Jyväskylä: University of Jyväskylä Press.

Maksimainen, J., \& Saariluoma, P. (2010). How Human Resource Management and Human Capital Management Influence Corporate Social Responsibility. International Journal of Knowledge, Culture and Change Management, 10, 111-126.

Maksimainen, J., \& Saariluoma, P. (2011). Expertise and Mental Contents of Value-Orientations - Outlining the Elements of Innovative Engineering. Proceedings of World Academy of Innovation and Management, 7-14.

Maksimainen, J., Saariluoma, P., \& Jokivuori, P. (2010). Corporate Social Responsibility and Values in Innovation Management. International Journal of Social Science, 5, 97-101.

McDowell, J. (1994). Mind and World. Cambridge, MA: Harvard University Press.

Mitchell, T.R., \& Scott, W.G. (1990). America's Problems and Needed Reforms: Confronting the Ethic of Personal Advantage. Academy of Management Executive, 4, 23-35.

Mitchell, T.R., \& O’Neal, M. (1994). Managing by Values: Is Levi Strauss' Approach Visionary - or Flaky? Business Week, Aug. 1, 46-52.

Moran, T. (1981). An Applied Psychology of the User. Computing Surveys, 13, 1-11. http://dx.doi.org/10.1145/356835.356836

Newell, A., \& Simon, H.A. (1972). Human Problem Solving. Englewood Cliffs: Prentice-Hall

Nord, W.R., Brief, A.P., Atieh, J.M., \& Doherty, E.M. (1988). Work Values and the Conduct of Organizational Behavior. In Staw, B. \& Cummings, L. (Eds.), Research in Organizational Behavior (pp. 1-42, 9). Creenwich: JAI Press.

O'Reilly, C.A., \& Chatman, J.A. (1996). Culture as Social Control: Corporations, Cults and Commitment. In Staw, B,. \& Cummings, L. (Eds.), Research in Organizational Behavior (pp. 157-200, 8). Greenwich: JAI Press.

Oulasvirta, A., \& Saariluoma, P. (2006). Surviving Task Interruptions: Investigating the Implications of Long-Term Working Memory Theory. International Journal of Human-Computer Interaction, 64, 941-961.

Payne, S.L. (1980). Organizational Ethics and Antecedents to Social Control Processes. Academy of Management Review, 5, 409-414. 
Postman, L., Bruner, J.S., \& McGinnies, E. (1948). Personal Values as Selective Factors in Perception. Journal of Abnormal and Social Psychology, 43, 142-154. http://dx.doi.org/10.1037/h0059765

Rokeach, M. (1968). Beliefs, Attitudes and Values. San Francisco, Washington, London: Jossey-Bass Publishers.

Rokeach, M. (1973). The Nature of Human Values. A Theory of Organization and Change. New York, NY: The Free Press.

Rokeach, M. (1979). Understanding Human Values. Individual and Societal. New York: The Free Press.

Rokeach, M., \& Ball-Rokeach, S.J. (1989). Stability and Change in American Values, 1969-1981. American Psychologist, 44, 775-784. http://dx.doi.org/10.1037/0003-066X.44.5.775

Saariluoma, P. (1990). Apperception and Restructuring in Chess Players' Problem Solving. In Gilhooly, K.J., Keane, M.T.G., Logie, R.H., \& Erdos, G. (Eds.), Lines of thought: Reflections on the Psychology of Thinking (pp. 41-57). London: Wiley.

Saariluoma, P. (1995). Chess players' thinking. London: Routledge.

Saariluoma, P. (1997). Foundational Analysis. London: Routledge.

Saariluoma, P. (2001). Chess and Content-Oriented Psychology of Thinking. Psicologia, 22, 143-164.

Saariluoma, P. (2002). Does Classification Explicate the Contents of Concepts? In I. Pyysiäinen, \& V. Anttonen (Eds.), Current Approaches in the Cognitive Science of Religion (pp. 229-259). London: Continuum.

Saariluoma, P. (2003). Apperception, Content-Based Psychology and Design. In U. Lindemann (Ed.), Human Behaviour in Design (pp. 72-78). Berlin: Springer.

Saariluoma, P., \& Nevala, K. (2006). The Focus of Content-Based Approach to Design Engineering - A Reply to Eder. AEDS Workshop Proceedings, University of Western Bohemia: Pilsen, 105-110.

Saariluoma, P. Nevala, K., \& Karvinen, M. (2006). Content-Based Analysis of Modes in Design Engineering. In Gero, J.S. (Ed.), Design, Computing and Cognition '06 (pp. 325-344). he Netherlands: Springer.

Schaffer, H. (1971). The Growth of Sociability. Penguin Books, Harmondsworth.

Schein, E.H. (1985). Organizational Culture and Leadership. San Francisco: Jossey-Bass.

Schwartz, S. (1992). Universals in the Content and Structure of Values. Theoretical Advances and Empirical Tests in 20 Countries. In Zanna, M. (Ed.), Advances in Experimental Social Psychology (pp. 1-65, 25). San Diego: Academic Press.

Schwartz, S., \& Bilsky, W. (1987). Toward a Universal Psychological Structure of Human Values. Journal of Personality and Social Psychology, 53, 550-562. http://dx.doi.org/10.1037/0022-3514.53.3.550

Searle, J.R. (1992). The Rediscovery of the Mind. Cambridge, MA: The MIT Press.

Sellars, W. (1956/1997). Empiricism and the Philosophy of Mind, edited by Brandom, R. Cambridge, MA: Harvard University Press, 1997.

Super, D.E. (1973). The Work Values Inventory. In Zytowski D.G. (Ed.), Contemporary Approaches to Interest Measurement. Minneapolis, MN: University of Minnesota Press, 189-205.

Thoman, E. (ed.) (1979). Origin of Infant Social Responsiveness. Hillsdale, NJ: Lawrence Erlbaum Associates.

Turing, A.M. (1936). On Computable Numbers, with and Application to the Entscheidungsproblem. Proceedings of the London Mathematical Society, 42, 230-265. http://dx.doi.org/10.1112/plms/s2-42.1.230

Turing, A.M. (1950). Computing Machinery and Intelligence. In Anderson, A.R. (Ed.), Minds and Machines. Englewood Cliffs: Prentice-Hall.

von Wright, G.H. (1963). The Logic of Preference. Edinburgh.

Vygotsky, L.S. (1962). Thought and Language. In Hanfmann, E. \& Vagar, G. (Eds. \& transl.), Studies in Communication. Cambridge, MA: The MIT Press.

Westermarck, E. (1891/1925). The History of Human Marriage I-II. London: Macmillan.

Wiener, Y. (1988). Forms of Value Systems: A Focus on Organizational Effectiveness and Cultural Change and Maintenance. Academy of Management Review, 13, 534-545.

Williams, R.M. Jr. (1979). Change and Stability in Values and Value Systems: A Sociological Perspective. In Rokeach, M. (Ed.), Understanding Human Values (pp. 15-46). New York: Free Press.

Wraga, M., \& Kosslyn, S. M. (2003). Imaginery. Encyclopedia of Cognitive Science, 466-470. London, New York, Tokyo: Nature Publishing Group. 